\title{
Alguns aspectos da cultura germânica num estudo sobre cartas familiares
}

\author{
Luciane Watthier* \\ Terezinha da Conceição Costa Hübes
}

\begin{abstract}
We conducted a study of language in the discursive genre family letter analyzing phonic, semantic and pragmatic peculiarities from the time they were written, as well as the identity of those involved in the interaction (writer and recipient). For this article, we selected two letters written by bilingual speakers of German and Portuguese to be analyzed, based on a study concerning the spread of Germanic culture in Brazil, having in mind that these letters reveal many aspects of this process.
\end{abstract}

Keywords: Germanic culture, identity, family letters.

Resumo: Realizamos um estudo da língua de comunicação usada no interior do gênero discursivo 'carta familiar' analisando peculiaridades fônicas e morfológicas da linguagem das cartas na época em que foram escritas, bem como da identidade das pessoas envolvidas no processo de interação (autor e receptor da carta). Para este artigo, são analisadas duas cartas escritas por falantes bilíngues de alemão e português, com base em uma reflexão sobre a difusão da cultura germânica no Brasil, tendo em vista serem essas cartas reveladoras desse processo.

Palavras-chave: cultura germânica, identidade, cartas familiares.

\footnotetext{
* Luciane Watthier é Mestranda em Letras na Universidade Estadual do Oeste do Paraná (UNIOESTE), Campus de Cascavel. E-mail: lu.letras@hotmail.com. Terezinha C. Hübes é Professora Doutora da Universidade Estadual do Oeste do Paraná (UNIOESTE), Campus de Cascavel. E-mail: terecostahubes@yahoo.com.br
} 


\section{Watthier, $L_{i}$ Hübes, T. - Cartas familiares}

\section{Introdução}

O presente estudo surgiu do interesse de compreendermos as razões históricosociais para casos de interferência morfofonêmica na língua de comunicação de descendentes de imigrantes alemães, fato que, ainda hoje, é perceptível em várias regiões brasileiras. Como a língua de comunicação é adquirida socialmente, creditamos a fatores sociais, políticos e culturais as causas da ocorrência desses fenômenos na linguagem.

O bilinguismo e a ocorrência de interferência morfofonêmica são características linguísticas observadas como fato corriqueiro em algumas regiões do Brasil após o século XIX, quando o governo promoveu a vinda de imigrantes europeus como forma de garantir mão de obra suficiente para substituir o trabalho escravo. Os imigrantes sentiam-se atraídos pelo serviço aqui oferecido e pelo potencial ainda não explorado de um país jovem, motivos pelos quais a imigração passou a ocorrer de forma muito rápida. Esses fatos acarretaram a vinda de pessoas oriundas de diversos países, especialmente europeus. Cada grupo de imigrantes trazia consigo sua cultura própria, identidades e línguas que se diferenciavam da cultura do país que os recebera.

Dessa forma, algumas regiões brasileiras podem ser consideradas plurilíngues e multiculturais. Dentro das comunidades de imigrantes, parte considerável é bilíngue, sendo uma a língua materna e a outra, a segunda língua. Nesse contexto, fatores sociais, políticos e culturais interferem no desenvolvimento linguístico de falantes dessas comunidades, peculiaridades essas que se refletem no campo fonético-fonológico das duas línguas, o que explica a ocorrência de interferência morfofonêmica de traços da língua materna na segunda língua, tanto na fala como na escrita. Pelo fato de a língua de comunicação ser adquirida no meio social, durante as interações verbais, algumas interferências morfofonêmicas assim geradas foram assimiladas por gerações mais novas. No estudo formal da segunda língua, alguns casos podem ser corrigidos, porém, em comunicações informais em que não há planejamento linguístico, tais casos de interferência, mesmo imperceptíveis ao falante, continuam a ocorrer de forma sistemática. 


\section{Watthier, Li Hübes, T. - Cartas familiares}

O presente estudo é parte de um projeto de mestrado iniciado em 2008, que analisa casos de bilinguismo situacional resultantes do contato entre duas línguas, o alemão (língua materna dos imigrantes) e o português (segunda língua), considerandose mais especificamente o português escrito por indivíduos que têm o alemão como língua materna. No âmbito do projeto, foram analisadas cartas pessoais e familiares produzidas por nossos antepassados, com o fito de buscar, nas narrativas pessoais e informais desse gênero epistolar, marcas reveladoras de história, cultura e identidade. $\mathrm{O}$ interesse pelo estudo desse corpus surgiu a partir da compreensão de que a linguagem nele contida representa aspectos da época em que é escrita, bem como da visão de mundo dos seus autores.

De um corpus composto de quarenta cartas familiares, coletado com o auxílio de professores, familiares e amigos, selecionamos, para ilustrar este trabalho, duas cartas escritas por descendentes de alemães, uma, escrita na década de 1940 (família Dariek aqui indicada como Cf.1) e a segunda, na década de 1980 (família Stulpen - Cf.2). Tal recorte histórico visa exemplificar aspectos da cultura, linguagem e identidade características de cada época considerada. Na década de 1940 do século passado, por exemplo, houve a proibição do uso de línguas de imigrantes no Brasil, no período conhecido como Era Vargas. Mas, mesmo com a proibição, traços linguísticos característicos da língua dos imigrantes estavam presentes em dadas situações enunciativas em suas cartas familiares, bem como os reflexos das proibições sofridas. Verificamos de que forma esses aspectos são perceptíveis por meio de relatos de fatos, de sentimentos e emoções descritos em exemplares ilustrativos desse gênero discursivo. O objetivo neste trabalho é, pois, apresentar uma reflexão sobre a imigração alemã no Brasil e a difusão de sua cultura, bem como compreender a influência de fatores externos à língua que impediram e dificultaram o processo pleno de aquisição do português pelos imigrantes de fala alemã.

O texto encontra-se estruturado da seguinte forma: no primeiro segmento, discorremos sobre as concepções de língua, identidade e cultura de uma forma geral. No segundo, sobre as especificidades da cultura germânica, abrangendo seu histórico de imigração no Brasil, a difusão de sua cultura no país e alguns fatores de cunho sóciocultural e político que influenciaram no uso da língua de comunicação de integrantes da 


\section{Watthier, Li Hübes, T. - Cartas familiares}

comunidade de imigrantes. No terceiro, apresentamos a análise das cartas familiares e, por último, tecemos algumas considerações a respeito.

\section{Reflexão sobre a interdependência entre língua, cultura $e$ identidade}

Refletir sobre a língua implica refletir, também, sobre aspectos culturais e identitários, pois língua, cultura e identidade se constituem a partir do social e não ao contrário. Além disso, essas três terminologias estão em uma relação de interdependência, uma vez que cultura e identidade só se manifestam por meio da língua, a qual, por sua vez, faz parte daquelas enquanto manifestações de um grupo social.

Para embasar este trabalho, valemo-nos das considerações teóricas de BAKHTIN (2004), para quem a necessidade de comunicação justifica a existência da língua, ou seja, ela se concretiza por meio da interação verbal, permitindo aos homens agir sobre o mundo e dizer o mundo, constituindo-o e sendo constituídos por ele. A língua é, portanto, uma atividade social, um conjunto de signos capaz de representar o real e um produto de uma necessidade histórica do homem, criado por ele para trocar experiências e de se organizar socialmente.

A língua é compreendida como um veículo de comunicação que se realiza por meio da interação social, representando a realidade circundante e, até mesmo, a forma como o falante a constitui, refletindo todas as suas mudanças e alterações sociais. Nesse sentido, a palavra é a "arena onde se confrontam os valores sociais contraditórios; os conflitos da língua refletem os conflitos de classe no interior do sistema” (BAKHTIN 2004: 15).

Assim, a língua não pode ser vista como um simples espelho, mas como a responsável por constituir a realidade, uma vez que, segundo as explanações de Bakhtin, a realidade passa a existir apenas por meio da interação verbal, dando vida à cultura e à identidade de um grupo social. Cultura e identidade só podem ser expressas pela língua e, segundo WoODWARD (2000), é só por meio dela e dos sistemas simbólicos que as representam adquirem sentido. Ao mesmo tempo, a linguagem como um todo necessita 


\title{
Watthier, $L_{i}$ Hübes, T. - Cartas familiares
}

da cultura para se manifestar, pois, conforme Koch, "toda e qualquer manifestação da linguagem ocorre no interior de determinada cultura" (Косн 1996: 36).

Desse ponto de vista, linguagem não é apenas língua, ou um mero conjunto de signos. É a responsável pela interação social e cultural, carregando consigo, de acordo com LOPES (1986), as ideologias de um grupo social produzidas pela sociedade, bem como os valores culturais e identitários de cada falante. Segundo Mello:

\begin{abstract}
Uma língua não é apenas um sistema de sons, um conjunto de unidades significativas dispostas em uma cadeia morfossintática. É muito mais do que um instrumento de comunicação. Uma língua é um comportamento social e como tal está intrinsecamente ligada à vida, à cultura e à história de um povo. São os falares, os modos de ser, os valores, as crenças que fazem com que os povos sejam diferentes ou semelhantes, porém singulares (MELLO 1999: 23).
\end{abstract}

Em outras palavras, a língua é constituída a partir do social, servindo como um reflexo das estruturas sociais, ou seja, em uma relação estreita entre língua e cultura, tem-se a primeira como a refletora da segunda e vice-versa. O mesmo vale para a identidade, uma vez que ela só é revelada por meio da língua, ao mesmo tempo em que a língua faz parte da identidade de um grupo social. Tudo o que temos na cultura e na identidade não passa de palavras, isto é, não existe, segundo Bakhtin, absolutamente nada na cultura, além da palavra: "toda cultura não é nada mais que um fenômeno da língua” (BAKHTIN 1988: 45).

Com base em Grosjean (1982), compreendemos também a cultura como um conjunto de valores de uma sociedade, desde sua língua até sua identidade, as quais estão intrinsecamente ligadas. A cultura abrange, portanto, "a maneira de vida das pessoas ou sociedade, incluindo suas regras de comportamento; seus sistemas econômicos, sociais e políticos; suas línguas; suas leis; e assim por diante" (GROSJEAN 1982: 157). Criada a partir desses valores, a identidade, por sua vez, é compreendida como um processo de identificação do Eu e de diferenciação entre o Eu e o Outro, por meio do qual um indivíduo se define socialmente e se reconhece dentro de um grupo social. O processo de construção da identidade é o que define a visão de um indivíduo em relação ao mundo que o cerca, como, também, a representação social de si mesmo e do outro. Neste sentido, LOPES (1986) explica que a sociedade é a fonte produtora das 


\section{Watthier, Li Hübes, T. - Cartas familiares}

ideologias, carregando consigo os valores culturais da sociedade de que esse indivíduo é membro, bem como da identidade de cada falante.

Podemos imaginar, portanto, uma ponte entre as definições de cultura e identidade. Cavalcanti recorre a SARUP (1996) para afirmar que é a cultura que nos forma: sem cultura não haveria identidade. Conclui-se, assim, que toda e qualquer representação "está inserida primeiramente na língua(gem) e depois na cultura" (CAVAlCANTI 2001: 52).

Ainda sob a mesma perspectiva, McLaren compreende que a formação da identidade se dá a partir das práticas sociais, enfatizando que "identidades envolvem articulações prediscursivas (material) e discursivas (semióticas) e estão sempre relacionadas às práticas sociais materiais de uma formação social mais ampla" (MCLAREN 2000: 46). Conforme o teórico, criamos, contextualizamos e recontextualizamos nossas identidades a partir de copadrões específicos de relações significativas e de seus usos. As identidades, ao expressarem nossas individualidades, expressam o meio em que vivemos.

Dito de outro modo, aspectos ideológicos e identitários podem ser perceptíveis ou recuperáveis por meio da leitura de textos escritos, mesmo ocorrendo a hibridização linguística, a qual pode ser observada quando duas ou mais línguas de um mesmo falante entram em contato, causando uma interferência da língua materna na escrita, na leitura ou na fala da segunda língua. Neste artigo, é nas cartas familiares que buscamos e analisamos tais características, observando de que forma a língua é reveladora das ideologias de um grupo social.

Como os remetentes das cartas do corpus de pesquisa são descendentes de alemães, passamos, no próximo segmento, a discutir sobre a imigração alemã e o enraizamento desses imigrantes no Brasil, buscando subsídios para a leitura e análise das cartas familiares aqui apresentadas.

\section{Imigração alemã no Brasil}

No Brasil, o processo de imigração ocorreu com maior intensidade a partir do século XIX, devido à abertura dos portos brasileiros às demais nações. Segundo VIDAL 


\section{Watthier, Li Hübes, T. - Cartas familiares}

(2007), com o término da escravidão, o país se tornou um cenário no qual a mão-deobra era escassa, enquanto a produção agrícola estava em alta, apresentando-se como uma nova alternativa de vida para a população que sofria com crises econômicas, impostos elevados, industrialização, desemprego, superpopulação e outros fatores que causavam fome, miséria e mortes. Em sua grande maioria, esses imigrantes vinham de países europeus (alemães, italianos, poloneses) e asiáticos (japoneses) e contribuíram para a formação de um país multicultural.

Os alemães foram um dos primeiros imigrantes vindos ao Brasil, uma vez que alguns agricultores alemães aqui chegaram em 1818, antes mesmo da regulamentação da imigração, que se deu em 1820. De acordo com VIDAL (2007), os imigrantes enfrentaram muitas dificuldades até se acomodarem como um novo grupo social. Seus problemas iniciaram-se com a longa viagem pelo Atlântico em condições desumanas, continuaram com a demora nos loteamentos e, talvez a mais difícil barreira a ser transposta tenha sido a língua; o desconhecimento da língua local dificultou a interação com a população brasileira. Como dito anteriormente, cada grupo social possuía uma cultura que o identificava, carregada por cada um de seus indivíduos. Assim, ao imigrarem para o Brasil, esses grupos trouxeram consigo sua própria cultura e, com ela, a língua e a identidade que lhe eram concernentes.

Por esse motivo, formaram-se colônias compostas por membros com uma língua em comum, no caso o alemão, fato que lhes facilitava a interação social, favorecendo, conforme a explanação de MANFrOI (1979), a homogeneidade étnica/cultural; o uso dos vários dialetos das regiões de origem desses imigrantes contribuiu para sedimentar a cultura alemã em bases sólidas, fator que explica por que essas colônias viveram, durante muito tempo, isoladas da população brasileira, como, por exemplo, no caso dos gaúchos ${ }^{1}$.

BORTONY e GUIMARÃES, ao realizarem uma pesquisa sobre os migrantes rurais em Brasília, estudaram o caso específico das colônias fechadas, afirmando que esses núcleos podiam favorecer "a conservação da cultura rural e, portanto, a focalização do vernáculo". Demonstram, assim, um alto nível de densidade moral ou consensual,

\footnotetext{
${ }^{1}$ Citamos os gaúchos, pois o Rio Grande do Sul foi o primeiro estado brasileiro a acolher os imigrantes alemães.
} 


\section{Watthier, Li Hübes, T. - Cartas familiares}

encontrada em sociedades tradicionais, o que funciona como um mecanismo de resistência à assimilação (BORTONY \& GUIMARÃES 1988: 27).

No contexto dos núcleos alemães, a igreja e a escola, onde se ensinava a ler, escrever e a calcular em língua alemã, foram importantes meios de preservação da cultura dos grupos de imigrantes no Brasil. Ainda hoje, esses meios são extremamente importantes para a sobrevivência da cultura nas cidades em que os imigrantes e seus descendentes se encontram.

Nesse sentido, a língua é uma marca decisiva de identidade grupal; na medida em que os imigrantes se dedicavam à preservação da língua alemã, mesmo estando fora de sua terra natal, reafirmavam-se enquanto indivíduos pertencentes à cultura alemã, diferenciando-se dos grupos sociais nativos de nossa terra. Conforme postula Spolsky:

\footnotetext{
Uma das formas de identificar uma pessoa é através de sua língua. Porque a língua está inerentemente envolvida na socialização, o grupo social cuja língua você fala é uma importante identidade grupal para você. Há outras marcas de identidade étnica, como comida ou roupa ou religião. Mas a língua tem um papel especial, em partes porque organiza o pensamento e em partes porque estabelece relações sociais (SPOLSKY 2003: 57).
}

Nas explanações de MENDES (2002), encontramos referências às necessidades de ligação e/ou diferenciação de um indivíduo/grupo social em relação a outro. Esse teórico fala nas forças centrípetas e centrífugas: a primeira diz respeito à necessidade de se ligar ao outro, ou seja, identificar-se com o outro, utilizando cultura e língua 'comum' a todos. Já a segunda é a necessidade de diferenciação do outro, marcada pela utilização de seus traços dialetais, étnicos e regionais, que, no caso dos imigrantes, na grande maioria das vezes ocorre como interferências linguísticas ou alternâncias fonológicas.

Essa diferenciação pode dar-se de forma forçada, quando o grupo difunde, propositalmente, sua cultura, identidade e língua próprias, excluindo os demais grupos sociais da interação verbal ou, mesmo, de forma natural, quando, por não conhecer as demais culturas, um grupo não consegue agir diferentemente do que lhe foi passado por sua cultura de origem étnica.

Se a cultura é um traço de identificação de um grupo social, ou seja, características e conhecimentos pertencentes a todos os seus membros, falamos das 


\section{Watthier, Li Hübes, T. - Cartas familiares}

forças centrípetas. Por outro lado, se a identidade é um traço de identificação adquirido a partir da cultura, entretanto, individual e variante de um membro para outro de um mesmo grupo social, falamos das forças centrífugas. Dessa forma, um grupo social, visto do exterior, tem a necessidade de se diferenciar de outro, passando a todos os membros os mesmos traços culturais, ao mesmo tempo em que, no seu interior, estes indivíduos diferenciam-se entre si conforme suas características identitárias.

Esses aspectos são tratados por teóricos da área como "diferença" enquanto constituinte da identidade, quer dizer, enquanto aspectos que marcam uma identidade e a diferenciam da outra. Nesse caso, só podemos ser marcados de uma forma se existem pessoas que se diferenciam de nós. WoOdWARD (2000) e SILVA (2000), em seus textos, tratam do assunto ao considerarem a diferença como um meio pelo qual as identidades são fabricadas, uma vez que, segundo as explanações de Silva, "identidade e diferença estão em uma relação de interdependência [...] na diferença se produz a identidade" (SILVA 2000: 75-76).

As diferenças identitárias seriam, portanto, características que permitem separar as identidades de um grupo social de outro e, segundo Woodward, "o componente chave em qualquer sistema de classificação" (WOODWARD 2000: 41), que, por sua vez, constrói significados, os quais dão sentido ao mundo social.

Para Semprini, esse sistema de classificação seria o multiculturalismo, pois o citado autor compreende a diferença como "uma realidade concreta, um processo humano e social, que os homens empregam em suas práticas cotidianas e que se encontra inserida no processo histórico" (SEMPRINI 1999: 11). A linguagem tem fundamental importância dentro do sistema de diferenciações: além de ser um meio pelo qual o mesmo é empregado, é um meio no qual a diferença é negociada, produzida e reproduzida.

Em um país como o Brasil, é a diferença entre os grupos sociais que o torna multicultural, que leva à formação de colônias devido à dificuldade de conviver com a diferença. No caso da imigração, esse processo pode passar da diferenciação entre identidades e culturas para uma assimilação e/ou mescla entre as mesmas, visto que, em algum momento, as colônias formadas por imigrantes poderão interagir com os grupos sociais nativos da terra. 


\section{Watthier, Li Hübes, T. - Cartas familiares}

Devido ao isolamento das colônias alemães em relação aos gaúchos, foi possível a construção de uma base para a difusão da cultura alemã entre seus membros. Entretanto, a mesma foi abalada com a ocorrência de guerras que levaram à repressão do uso dessa língua durante a Era Vargas.

O primeiro fator responsável por isso foi a Primeira Guerra Mundial, quando o Brasil se posicionou contra a Alemanha, em 1917, auxiliando, com enfermeiros e remédios, a tríplice Entente, formada pela França, pela Rússia e pelo Reino Unido, que lutava contra a tríplice Aliança, formada pela Itália, pelo Império Austro-Húngaro e pela Alemanha. Os governantes do momento evocaram, de acordo com ROCKENBACK (2004), por meio de uma campanha nacionalista, a necessidade de domínio da língua portuguesa, promovendo ações políticas, como a implantação de escolas públicas, o fechamento de escolas e associações junto com o afastamento de professores e a proibição da imprensa em língua alemã.

Mas, apesar de todos os meios de repressão que abalaram a estrutura da cultura germânica no Brasil, ao final da guerra, os imigrantes se reorganizaram e voltaram a difundir sua cultura de origem, assim como faziam antes da guerra. Porém, outro fator desestruturou essas bases antes mesmo do início da Segunda Guerra Mundial. O responsável foi Getúlio Vargas, que governou o Brasil entre 1930 e 1945, reprimindo a cultura e a língua alemã por meio de uma campanha nacionalista que exigia o domínio e uso da língua portuguesa pelos imigrantes. Isso aconteceu em 1937, com a instituição, por Getúlio Vargas, do Estado Novo e a proibição do uso de qualquer língua estrangeira, bem como de bandeiras e outros símbolos estrangeiros, fazendo com que dezenas de escolas responsáveis pelo ensino e difusão da cultura alemã fossem fechadas.

A repressão foi, entretanto, ainda maior quando o Brasil entrou, oficialmente, na Segunda Guerra Mundial, em 1942. Iniciou-se a perseguição aos imigrantes alemães e houve o fechamento de sociedades culturais com o confisco de bandeiras, escudos, medalhas e bibliotecas.

Semprini, ao trabalhar com a imigração nos Estados Unidos, fala do racismo “gota de sangue" (SEMPRINI 1999: 17), um processo de exclusão sofrido pelo indivíduo por causa de sua ascendência, ou seja, um indivíduo é considerado negro, apesar de sua aparência branca, pelo simples fato de ter um bisavô negro. No contexto dos imigrantes 


\section{Watthier, Li Hübes, T. - Cartas familiares}

alemães, esse processo ocorreu de uma forma um pouco diferente. Mesmo sendo nascido no Brasil, se um indivíduo tivesse o sobrenome de origem alemã, era vítima de racismo, não podendo nem mesmo casar-se com um nativo. As perseguições e repressões à cultura alemã foram responsáveis pela perda de parte dessa cultura, uma vez que, ao final da guerra, a mesma não pôde mais ser restabelecida nos moldes anteriores, assim como ocorrera após a Primeira Guerra Mundial.

SEMPRINI (1999) explica que conflitos sofridos pelos imigrantes alemães no Brasil provocaram incertezas e ansiedades. Assim, o medo de que a nacionalidade brasileira se perdesse com a afirmação da cultura alemã levou à imposição da política de nacionalização. Conforme VIDAL (2007), além de desestruturarem a cultura alemã colonial da época, as repressões causaram marcas na identidade dos imigrantes, pois falar alemão ou cultivar suas tradições, até mesmo no meio familiar, era visto como crime que resultava em prisão, sendo considerado ameaça à ideia de nacionalidade brasileira. Resultados desse processo podem ser observados, conforme VIDAL (2007), na geração que cresceu sob tais conflitos, a qual é incapaz de dominar a língua alemã falada na infância, sem saber, suficientemente, o português para uma escrita normativa.

A dificuldade encontrada pelos imigrantes alemães na escrita deve-se ao fato de que parte de sua aprendizagem realizou-se, mesmo no Brasil, em língua alemã e, após o fechamento das escolas e a proibição deste tipo de ensino, o restante da aprendizagem deu-se em língua portuguesa. Com as restrições feitas ao uso e cultivo da língua alemã, os imigrantes iniciaram o contato com a língua e a cultura do povo brasileiro, obrigando-se a conviverem com novas formas de vida, novos costumes e novos valores, deixando para trás, pelo menos durante o período de repressão, cultura e língua próprias de seu grupo social.

Desse modo, ao entrarem em contato com os habitantes do novo país, os imigrantes assimilaram alguns de seus traços culturais e identitários, mesclando valores e características dos dois países, o que, em longo tempo, fez surgir novas culturas e novas identidades. BORTONI-RICARDO, ao fazer uma análise sociolinguística da imigração no Brasil, expõe as transformações na cultura dos imigrantes, afirmando que aqueles que chegam "à cidade já como adultos alteram certas características de seu dialeto original. Esse processo é influenciado pelos padrões de sua socialização no novo habitat [...]" (BORTONI-RICARDO 2005: 102). 


\section{Watthier, $L_{i}$ Hübes, T. - Cartas familiares}

Assim, os imigrantes alemães, por serem obrigados a utilizar o português, passaram por processos de misturas de línguas entre o alemão e o português para que a interação verbal pudesse acontecer. Conforme BORTONI e GUIMARÃES, isso ocorre porque os imigrantes têm a consciência de que "a escolarização, e consequentemente o conhecimento da língua padrão, são necessários para a mobilidade social" (BORTONI \& GUIMARÃES 1988: 25). Os autores mencionam o uso da língua padrão porque trabalham com a migração rural-urbana e os migrantes, chegando à cidade, com variações dialetais, devem aprender a língua padrão para uma inserção naquela comunidade. No caso do tema aqui abordado verifica-se o mesmo processo, com a diferença de que, nessa situação, a língua a ser aprendida é um novo idioma.

Surge, então, o fenômeno da interferência linguística, ou seja, a inserção de traços fonológicos e morfológicos da língua materna na escrita e/ou na fala da segunda língua. O contato entre línguas ocorre quando se tem um falante bilíngue ${ }^{2}$ que interage em uma língua que não é a materna e utiliza traços fonológicos desta naquela, ou durante a aprendizagem de um indivíduo bilíngue quando interferências prejudicam a aquisição tanto de uma quanto de outra língua, como aconteceu com os imigrantes alemães no Brasil. Mello, em um estudo sobre o falar bilíngue, afirma que o movimento migratório é uma das principais causas para ocorrência de situações que resultam em bilinguismo ou multilinguismo, pois "a língua de origem continua sendo usada entre familiares e aqueles que compartilham as mesmas raízes, enquanto a língua da comunidade local é adquirida para uso nas demais interações” (MELlo 1999: 34).

\footnotetext{
${ }^{2}$ Caracterizamos um indivíduo como bilíngue quando é capaz de se comunicar em duas línguas e multilíngue quando se comunica em três ou mais línguas. Há, entretanto, quanto a estes conceitos, uma grande variação nas definições entre os linguistas, havendo aqueles que, para classificar um indivíduo como bilíngue, exigem que ele tenha o domínio completo de ambas as línguas, assim como um falante nativo, como defende Bloomfield: "bilíngue é o indivíduo que tem habilidade de falante nativo em duas ou mais línguas" (BLOOMFIELD 1933: 56). Por outro lado, há aqueles que concordam que um domínio menor dessas línguas é suficiente para que ocorra uma situação de bilinguismo, conforme defende MACKEY (1968), que considera o bilinguismo desde "uma competência mínima até um domínio completo de mais de uma língua" (MACKEY 1968: 555).

Ao fenômeno da interferência linguística, Silva-Corvalan prefere chamar de transferência linguística, por acreditar que esta tenha uma conotação mais positiva em relação à outra. A teórica considera, portanto, que este fenômeno ocorre "quando uma língua evidencia desvios ou diferenças da norma linguística monolíngue que correspondem a estruturas existentes na língua em contato" (SILVA-CORVALAN 1989: 170).
} 


\section{Watthier, $L_{i}$ Hübes, T. - Cartas familiares}

Esses aspectos podem ser percebidos na leitura de textos informais, uma vez que, neste caso, ocorre uma escrita mais próxima a da comunicação do dia-a-dia. Portanto, em cartas familiares escritas por imigrantes e seus descendentes em comunidades de pequenos grupos étnicos aparecem traços de interrupções, digressões, repetições e o uso bilíngue e bidialetal dos elementos prosódicos e traços de segmentos linguísticos do falar da língua materna deste grupo e do português brasileiro que, a partir da competência comunicativa, caracterizam os procedimentos constitutivos da oralidade. Como cita Hymes, a competência comunicativa "é aquela que se refere ao conhecimento e uso da estrutura da língua. É um conhecimento comumente inconsciente e mostrado na fala espontânea" (HYMES 1972: 270), dos usuários de dois códigos linguísticos, como ocorre em pequenos grupos, comunidades de imigrantes e seus descendentes.

Considerando o exposto, os processos pelos quais se formam a cultura e as identidades de um grupo social possuem fortes relações entre si. Os aspectos são revelados na escrita de textos e, em especial, nos informais, como as cartas familiares, corpus do estudo. É o que mostramos no próximo segmento.

\section{Análise do corpus: fatores culturais e identitários}

Considerar a língua como um veículo por meio do qual os indivíduos interagem possibilita a compreensão de que a língua é um veículo de interação comunicativa que reflete o mundo e a visão de cada sujeito em relação ao mesmo. Assim, uma carta familiar, por exemplo, produz uma representação da realidade circundante e, até mesmo, de sua visão sobre esse meio.

As cartas analisadas neste estudo nos foram cedidas pelas próprias famílias a que elas pertencem. Uma delas pela família Dariek e a outra pela família Stulpen ${ }^{3}$.

A carta da família Dariek (doravante Cf.1) foi escrita por Ivone a seu irmão, Juca, no dia 14 de maio de 1944. Ivone morava em São Paulo, SP e escreveu a Juca

\footnotetext{
${ }^{3}$ Os nomes aqui apresentados são fictícios.
} 


\section{Watthier, $L_{i}$ Hübes, T. - Cartas familiares}

quando ele estava no seminário, em Santa Maria, RS. O texto integral encontra-se em anexo:

A carta da família Stulpen, supracitada (doravante Cf.2), não traz exatamente o ano em que foi escrita. No entanto, com base em informações cedidas pela família, chegamos à conclusão de que isso ocorreu no ano de 1987, visto que Gema, a remetente da carta, tinha 56 anos quando a escreveu e, hoje, se viva, teria 78 .

Ao lermos as correspondências, observamos que ambas foram escritas como o objetivo de relatar notícias sobre a família, já que remetentes e destinatários moravam distantes um do outro e a forma mais acessível de manter contato era por meio de cartas, devido ao difícil acesso ao telefone.

Ivone e Juca (Cf.1) eram irmãos, católicos, descendentes de alemães e vindos de uma família que tinha na agricultura e na criação de animais seu sustento, pois Ivone conta a Juca - afastado desse meio por estar estudando no seminário -, que criavam porcos e galinhas, além de plantarem feijão, tudo para sustento próprio e, também para venda:

[...] Oche nos vazeo dinheiro venteo 2 borcos. Emílio Brieger é no negosio do cuhu em San Paulo ele drabalha lá nos temos 24 borcos e 40 galinhas vendeo vichon pra $800 \$ 500$ um saco pra $50 \$ 000 "$. Alfonso Has voi no dotor - ele foi muinto doente. O medrio resebi carta de ti [...] (Cf.1)

O fato de "fazer dinheiro" para essa família era novidade, tanto que merecia ser relatado em carta, revelando, assim, as dificuldades financeiras enfrentadas por eles. Além disso, a correspondência ainda comprova que, para essa família, era costume a comunicação via cartas. Isso pode ser percebido quando a remetente não especifica a doença de Alfonso e quando fala que seu primo recebeu uma carta de Juca, dando a entender que sua carta era a continuação de assuntos já iniciados em cartas anteriores.

Assim como Ivone, também Gema (Cf.2) era agricultora. Porém, para ela, isso dificultava a comunicação com seus familiares habitantes de outras cidades, pois trechos da carta revelam que há muito tempo Gema e não trocava correspondências com sua sobrinha, a remetente da carta: 


\section{Watthier, $L_{i}$ Hübes, T. - Cartas familiares}

O meu pai falleceu no dia 12 de novembro de 1972. E a mãe falesceu no dia 06 de março de 1979. E a irmã mais velha falesceu no dia 20 de fefereiro de 1977 e a Olívia falesceu no dia 06 de april de 1982. [...] Nós trabalha ainda na roça. Nós planta de tuto, nós tem 10 cabeça gado e porco. Nós vende leite [...] (Cf. escrita por Gema em 10 de janeiro de 1987).

O que nos permite compreender que remetente e destinatário da Cf.2 já não tinham contato há muito tempo é o fato de relatarem falecimentos que ocorreram muito tempo antes da data em que a carta foi escrita (1987). Isso nos permite inferir, ainda, que, na época, o telefone ainda era de difícil acesso, principalmente aos habitantes da zona rural.

Por outro lado, as transcrições revelam, claramente, a dificuldade que Ivone (Cf.1) e Gema (Cf.2) tinham em escrever na língua portuguesa por serem imigrantes alemãs e terem o costume de utilizar somente o alemão no dia-a-dia. Dessa forma, ocorria uma mistura entre essas duas línguas e as palavras de grafia desconhecida em português eram escritas em alemão, como pode ser observado no recorte da Cf.1, quando, além de contar a seu irmão que eles haviam vendido porcos e feijão, Ivone fala que seu primo estava trabalhando em São Paulo, provavelmente com criação de gado, que a missivista chama de "negocio do cuhu", usando, claramente, a palavra alemã em lugar do termo "vaca" em português.

Tais marcas da cultura alemã revelam-se, ainda, na grafia de algumas palavras, que refletem a linguagem oral corrente na comunidade de imigrantes: oche (hoje), venteo (vendeu), borcos (porcos), drabalha (trabalha), april (abril), tuto (tudo), fefereiro (fevereiro). Essa característica explica-se pelo fato das missivistas terem sido alfabetizadas em língua alemã e terem aprendido português em situação informal, a partir de seu cotidiano. Desse modo, eles apresentavam uma mistura entre a língua alemã e o português, demonstrando dificuldades tanto na fala quanto na grafia do português, uma vez que aquilo que escreviam era um reflexo do modo como se comunicavam no cotidiano:

[...] Hoje no dia 10 de janeiro eu guero resonder a tua carta gue tu escreveu para min. A paula e eu morra junto já faís 10 ano que eu esta com a perna quebrada. E não da bem certo mãs assim vai tudo bem [...]" (Cf.2) 


\section{Watthier, Li Hübes, T. - Cartas familiares}

Talvez essas interferências detectadas na escrita das missivistas possam ser explicadas através de fatos históricos, pois, como anteriormente mencionado, entre os anos de 1930 e 1945, com o governo de Getúlio Vargas no Brasil e a Segunda Guerra, houve a proibição do uso de línguas de imigrantes. Essa é a época em que, entre os imigrantes ligados originalmente às nações integrantes do Eixo, falar em outro idioma, até mesmo no meio familiar, era considerado um crime que resultava em prisão. Isso explica, nesse contexto, as suas inúmeras dificuldades de comunicação escrita e oral.

A língua alemã, internalizada nessas pessoas, dificultou a expressão em português, marcada pela mistura de traços fonéticos-fonológicos, morfológicos e lexicais de uma língua na outra. A língua de origem era o que identificava essas pessoas como pertencentes ao seu grupo social, portadora das marcas da cultura e da identidade desse povo. Como já destacamos em Spolsky (vide citação no item 3 do trabalho), ela é uma marca de identidade grupal.

No caso das cartas analisadas, em que ocorre o contato entre o alemão e o português, percebe-se a troca de traços surdo/sonoro: [ $\mathrm{t}$ ] por [ $\mathrm{d}$ ], de [ $\mathrm{b}$ ] por [ $\mathrm{p}$ ], de [ $\mathrm{g}$ ] por [ k ] e de [ v ] por [ f ] (tuto por tudo, brecisa por precisa, april por abril, guero por quero, oche por hoje, voi por foi, fefereiro por fevereiro, só para citar alguns exemplos), além da inserção de lexemas em português em meio ao texto em alemão, como observamos na transcrição de alguns trechos da Cf.1. Aspectos como esses são fenômenos de interferências morfofonêmicas e alternância de código.

Devido aos aspectos apontados, podemos inferir que as missivistas eram pessoas simples, batalhadoras e pouco instruídas, pois, caso contrário, teriam aprendido o idioma do país, mesmo morando em um local onde a comunicação em alemão era comum. Porém, por morarem na lavoura e distante da cidade, provavelmente o acesso ao estudo lhes era difícil, o que fez com que o aprendessem a segunda língua em seu cotidiano, ocorrendo a mistura entre as duas línguas.

Sendo assim, compreendemos parte de sua cultura condicionada à época: somada a essa distância dos centros de formação, havia a dificuldade de locomoção e a crença de que, ao viver na zona rural, as pessoas não precisariam de uma educação formal para trabalhar nesse meio. É o que o recorte a seguir revela: “[...] Agora tu me escreve, que profisão ele tem. Ele tem estuto ou ele trabalha na roça, tem terra [...]" (Cf.2) 


\section{Watthier, Li Hübes, T. - Cartas familiares}

Quando se trabalhava na lavoura, não havia uma grande preocupação em estudar. Essa concepção de vida era incentivada pelo fato de que esses imigrantes moravam em comunidades fechadas, onde predominava a cultura trazida do país de origem: utilizavam seus dialetos, sem o contato direto com a cultura local, bem como com os nativos daquelas terras. Isso causava, segundo BORTONY \& GUIMARÃES (1988), uma resistência à assimilação, ao mesmo tempo que, conforme postula MANFROI (1979), possibilitava a formação de uma base para a cultura alemã.

Desse modo, observamos, na prática, o teorizado anteriormente, ou seja, que a língua é responsável pela reflexão e refração da realidade. Marcuschi corrobora para essa visão ao afirmar:

[...] a língua, seja na sua modalidade falada ou escrita, reflete, em boa medida, a organização da sociedade. Isso porque a própria língua mantém complexas relações com as representações e as formações sociais. Não se trata de um espelhamento, mas de uma funcionalidade em geral mais visível na fala (MARCUSCHI 2007: 35).

\section{Considerações finais}

Sendo a escrita repleta de marcas da identidade das pessoas envolvidas nas enunciações, bem como da cultura da época em que as mesmas foram escritas, observamos na prática o que foi antes teorizado. Por meio da leitura da carta analisada, temos uma visão da cultura da época em que ela foi escrita e, também, da identidade das pessoas envolvidas nesse processo de situação comunicativa. Em outras palavras, é apenas por meio de práticas sociais realizadas pela língua que a realidade passa a existir.

Por esse motivo, consideramos as cartas familiares como documentos de valor histórico inestimável, pois, sendo produzidas a partir de um contexto comunicativo em que desponta a cultura e a identidade própria de seu missivista, são portadoras, portanto, de marcas capazes de recuperar essas características.

A ideia de língua como ação social reveladora de aspectos culturais e identitários da época em que foi produzida é corroborada por Koch, segundo a qual "os fenômenos sociais são fenômenos linguísticos de alguma forma, assim como os fenômenos linguísticos são, em parte, sociais” (КоCH 1996: 59). 


\section{Watthier, $L_{i}$ Hübes, T. - Cartas familiares}

Concordamos, também, com BAZERMAN (2006), de que as cartas familiares estão abertamente ligadas às relações sociais e a autores particulares, tornando-se um material riquíssimo em particularidades de uma época e da cultura de um povo. Além disso, expressam, na maior parte das vezes, a modalidade mais natural da comunicação humana, ou seja, uma "conversa" informal, na qual é possível observar as mais espontâneas manifestações de interferência linguística. Consideramos, pois, a carta familiar como um material precioso, revelador de aspectos e peculiaridades da época em que foram escritos, bem como da identidade das pessoas envolvidas nessa situação comunicativa. Entretanto, apesar da informalidade, naturalidade e uso do linguajar típico da oralidade, características encontradas na carta familiar, não se deve avaliá-las como textos sem relevância para a constituição de um corpus acadêmico. Pelo contrário, são discursos ricos em relações sociais, uma vez que essa organização é um reflexo dos modos como interagimos verbalmente no nosso cotidiano. Para Bazerman, a organização das cartas familiares "só significa que elas nos revelam clara e explicitamente a sociabilidade que faz parte de toda escrita" (BAZERMAN 2006: 99).

\section{Referências bibliográficas}

BAKHTIN, Mikhail. Marxismo e filosofia da linguagem: problemas fundamentais do método sociológico na ciência da linguagem. Trad. Michel Lahud e Yara F. Vieira. 11 a . ed. São Paulo: Hucitec, 2004.

BAKHTIN, Mikhail. Questões de literatura e de estética: a teoria do romance. Trad.

Aurora F. Bernardini et.al. São Paulo: Hucitec, 1988.

Bazerman, Charles. Cartas e a base social dos gêneros diferenciados. In: Dionísio, Ângela Paiva; Hoffnagel, Judith Chambliss (org.). Gêneros textuais, tipificação e interação. Trad. Judith C. Hoffnagel. $2^{\text {a }}$ ed. São Paulo: Cortez, 2006, 83- 99.

BloOMFIELD, L. Language. New York: Holt, Rinehart \& Winston, 1933.

BortONI-RICARDO, Stella Maris. Nós cheguemu na escola, e agora?: Sociolinguística e educação. São Paulo: Parábola Editorial, 2005.

Bortoni, Stella Maris; GUIMARÃEs, Lytton Leite. Mudança linguística e redes sociais: um estudo exploratório de migrantes rurais em Brasília. In: Hamel, Rainser Enrique; Suárez, Yolanda Lastra de; Cruz, Héctor Muñoz (eds). Sociolinguística Latinoamericana - X Congresso Mundial de Sociologia. Universidad Nacional Autónoma de México, 1982.

Cavalcanti, Marilda C. Considerações sobre alguns cenários sociolinguisticamente complexos no contexto brasileiro: o andamento do projeto "vozes na escola". In: Linguas \& Letras. Cascavel, Edunioeste, 2001, v.2, no.2, 43-66. 


\section{Watthier, Li Hübes, T. - Cartas familiares}

Grosjean, F. Life with two languages: An introduction to bilingualism. Cambridge: Harvard University Press, 1982.

HYMES, D. Sociolinguistics. Harmondsworth: Penguin, 1972.

KocH, Ingedore G. Villaça. Estratégias pragmáticas de processamento textual. In: Rajagopalan, Kanavill (Org.). Cadernos de Estudos Lingüísticos. Campinas, jan/jun. 1996, no. 30, 35-42.

LOPES, Edward. Fundamentos da Linguística Contemporânea. São Paulo: Cultrix, 1986.

MACKEY, W. F. The description of bilingualism. In: Fishman, J. A. (Ed.). Readings in the sociology of language. Haia, Mouton, 1968. 554-84. Manfroi (1979)

McLaren, Peter. Multiculturalismo crítico. $3^{\text {a }}$. ed. Trad. Bebel Orofino Schaefer. São Paulo: Cortez, 2000.

MARCUSCHI, Luiz Antônio. Fenômenos da linguagem: reflexões semânticas e discursivas. Rio de Janeiro: Lucerna, 2007.

Mello, Heloísa Augusta Brito de. O falar bilíngue. Goiânia: Ed. da UFG, 1999.

Mendes, José Manuel Oliveira. O desafio das identidades. In: Santos, Boaventura de Sousa Santos (Org.). A globalização e as ciências sociais. $2^{\mathrm{a}}$ ed. São Paulo: Cortez, 2002, 503-540.

RoCKENBACK, Silvio Aloysio. Imigração alemã: 180 anos - história e cultura. Silvio Aloysio Rockenback; Hilda Agnes Hübner Flores. Porto Alegre: Corag, 2004.

SEMPRINI, Andréa. Multiculturalismo. Trad. Laureano Pelegrin. Bauru, SP: EDUSC, 1999.

Silva, Tomaz Tadeu da. A produção social da identidade e da diferença. In: Silva, Tomaz Tadeu da (Org.). Identidade e diferença: a perspectiva dos estudos culturais. Petrópolis, RJ: Vozes, 2000.

Silva-Corvalan, C. Sociolinguística: teoría y análisis. Buenos Aires: Alhambra, 1989.

SPOLSKY, B. Sociolinguistics. New York: Oxford University Press, 2003.

VIDAL, Sirlei Lopes. Ações de políticas linguísticas na revitalização da língua alemã em Agudo-RS. In: Anais do I Fórum Internacional da Diversidade Linguística. Porto Alegre: Universidade Federal do Rio Grande do Sul, 2007, 937 - 944.

WoODWARD, Kathryn. Identidade e diferença: uma introdução teórica e conceitual. In: Silva, Tomaz Tadeu da (Org.). Identidade e diferença: a perspectiva dos estudos culturais. Petrópolis, RJ: Vozes, 2000, 07-72. 


\section{Watthier, L; Hübes, T. - Cartas familiares - Anexos}

Anexos

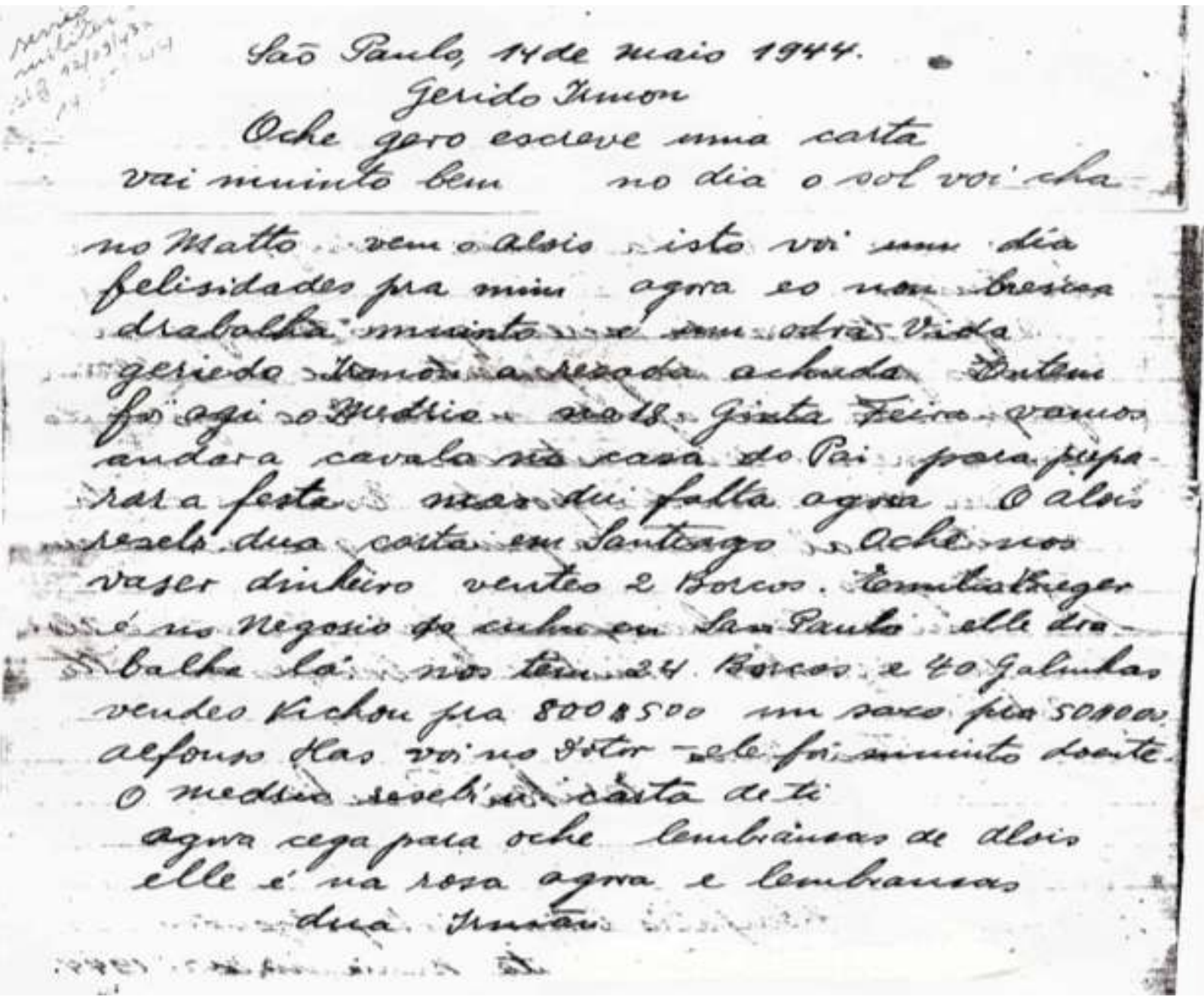


Watthier, Li Hübes, T. - Cartas familiares - Anexos

hijo no dia 10 de fanoisorece gram

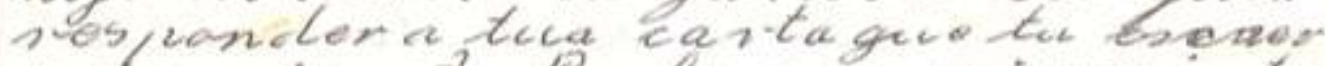
parumin. to Pawla e ou màna junto

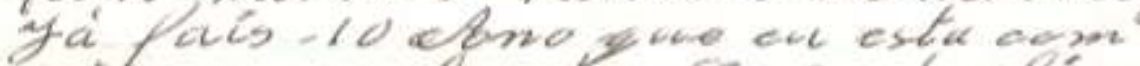

perna quebrada. Émä́d la bán corto ¿lias assiom vai tudo lem.

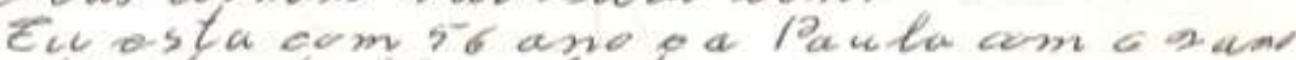
cpis tratalia céprda na rague

abs izlanta de tivto mois tom 10

cabega gado parar. pas vende hocto

Sobrintas moce estara em Panascoi on Vita Eristab. Zgora tu, me resoreve

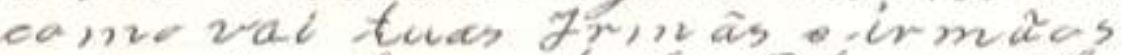

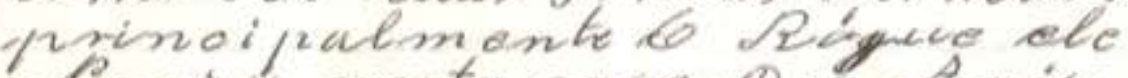

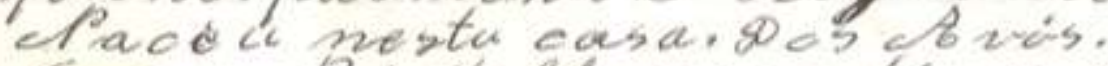

O mocr lac falloceo molia 12 do

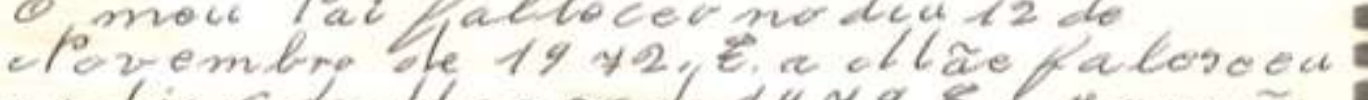
no lio 6 fe llargo de $147 \%$. mais welha palesceono diale lofinow

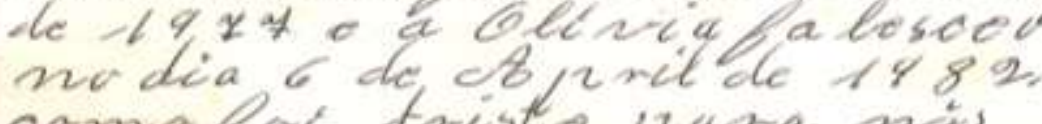
oamafac tristo jusa nas

- firnar mace mana bom zejota - le noss. Eveles a stão bens elds foy

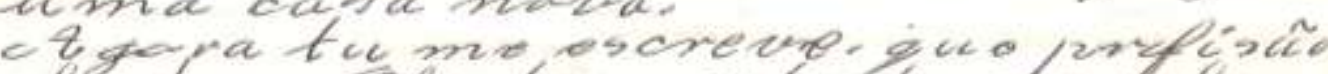
ele tem Ele tem est cito ock ble Para min é olificul miajar

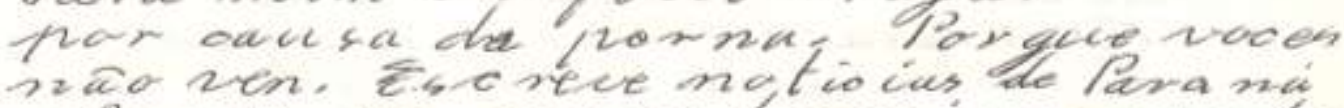

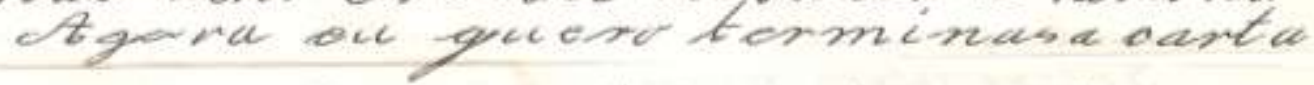

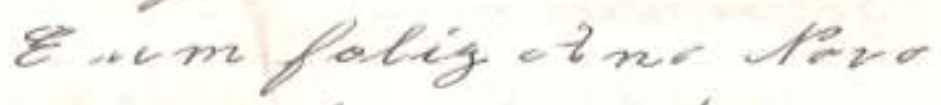

clluctus Iombrangers de min

$$
\text { Enderegr }
$$

Santa quecar Rio frandeda Sul 